\title{
Effect of Acute and Chronic Alcohol Treatment and Their Superimposition on Lysosomal, Cytoplasmic, and Proteosomal Protease Activities in Rat Skeletal Muscle In Vivo
}

\author{
M. Koll, S. Ahmed, D. Mantle, T.M. Donohue, T.N. Palmer, U.A. Simanowski, \\ H.K. Seitz, T.J. Peters, and V.R. Preedy
}

\begin{abstract}
Alcohol can be considered as a nutritional toxin when ingested in excess amounts and leads to skeletal muscle myopathy. We hypothesized that altered protease activities contribute to this phenomenon, and that differential effects on protease activities may occur when: (1) rats at different stages in their development are administered alcohol in vivo; (2) acute ethanol treatment is superimposed on chronic alcohol-feeding in vivo; and (3) muscles are exposed to alcohol and acetaldehyde in vivo and in vitro. In acute studies, rats weighing approximately $0.1 \mathbf{~ k g}$ (designated immature) or approximately $0.25 \mathbf{~ k g}$ (designated mature) body weight (BW) were dosed acutely with alcohol (75 mmol/kg BW; intraperitoneal [IP], 2.5 hours prior to killing) or identically treated with $0.15 \mathrm{~mol} / \mathrm{L} \mathrm{NaCl}$ as controls. In chronic studies, rats (approximately $0.1 \mathrm{~kg} \mathrm{BW}$ ) were fed between 1 to 6 weeks, with $35 \%$ of dietary energy as ethanol, controls were identically treated with isocaloric glucose. Other studies included administration of cyanamide (aldehyde dehydrogenase inhibitor) in vivo or addition of alcohol and acetaldehyde to muscle preparations in vitro. At the end of the treatments, cytoplasmic (alanyl-, arginyl-, leucyl-, prolyl-, tripeptidylaminopeptidase and dipeptidyl aminopeptidase IV), lysosomal (cathepsins B, D, H, and L, dipeptidyl aminopeptidase I and II), proteasomal (chymotrypsin-, trypsin-like, and peptidylglutamyl peptide hydrolase activities) and $\mathrm{Ca}^{2+}$-activated (micro- and milli-calpain and calpastatin) activities were assayed. (1) Acute alcohol dosage in mature rats reduced the activities of alanyl-, arginyl- and leucyl aminopeptidase (cytoplasmic), dipeptidyl aminopeptidase II (lysosomal), and the chymotrypsin- and trypsin-like activities (proteosomal). No significant effects were observed in similarly treated immature rats. (2) Alcohol feeding in immature rats did not alter the activities of any of the enzymes assayed at 6 weeks. (3) In immature rats, activities of cathepsins B and D were not overtly affected at either 3, 7, 14, 28, or 42 days. (4) Superimposing acute (2.5 hours) on chronic (4 weeks feeding of immature rats) ethanol treatment (ie, chronic + acute) reduced the activities of cytoplasmic proline aminopeptidase and the chymotrypsin- and trypsin-like activities of the proteasome. (5) Cathepsin D activities were reduced in muscle homogenates upon addition of alcohol and acetaldehyde in vitro. (6) Cyanamide pretreatment in combination with alcohol dosage in immature rats did not significantly alter any protease activities. The data suggests that mature rats are more sensitive to the effects of acute alcohol on muscle proteases. Protease activities may be affected by acetaldehyde or alcohol levels as indicated by in vitro experiments. The reduction in muscle protease activities in chronic + acute alcohol superimposition may reflect the effect of acute alcohol dosage alone. Overall, there was no evidence for increased protease activity in any of the experimental situations.
\end{abstract}

Copyright $\odot 2002$ by W.B. Saunders Company

$\mathbf{A}^{\mathrm{L}}$ COHOLIC MUSCLE DISEASE is one of the most common pathologies caused by alcohol abuse, and affects between one half and two thirds of all alcohol abusers. ${ }^{1-3}$ The diameter of type 2 (glycolytic, fast-twitch, anaerobic) fibers is reduced in contrast to type 1 fibers, which appear to exhibit a mild hypertrophy in the initial stages of alcoholic exposure and atrophy in severe cases. ${ }^{4}$ The reductions in fiber diameters are associated with decreases in muscle protein content, protein/ DNA ratios, myosin heavy chain content, midarm circumference, urinary creatinine excretion, and the body mass (ie, Quetelet's) index. ${ }^{5-9}$ Disturbances in protein turnover are, therefore, implicated in the pathogenesis of alcoholic myopathy. ${ }^{10}$

However, while alcohol-induced changes in muscle protein synthesis are well characterized, ${ }^{4,11-14}$ protein degradation has received little attention. One study found that 24 hours after alcohol administration, the activities of 2 cytoplasmic proteases (ie, alanyl aminopeptidase and tripeptidyl aminopeptidase) decreased compared with controls, whereas other cytoplasmic or lysosomal proteases were not significantly affected. ${ }^{15}$ In human alcoholic subjects, a decrease in protein breakdown has been shown via analysis of urinary 3-methylhistidine. ${ }^{7}$ In contrast, in uremic rats exposed to alcohol for 4 weeks, the activities of alkaline myofibrillar proteases and cathepsin D were increased. ${ }^{16}$ However, calculation of the fractional rate of protein breakdown, as the difference between fractional growth rate and fractional synthesis rate, indicated a decrease in protein breakdown in chronic (ie, 6 week) alcohol-treated rats. ${ }^{17}$ The addition of supraphysiologic levels of alcohol or acetaldehyde added to human muscle tissue homogenates in vitro results in decreased activities of a range of cytoplasmic and lysosomal proteases. ${ }^{18}$ Overall, these data suggest a decrease in the rate of

From the Department of Nutrition and Dietetics, King's College London, London; Department of Clinical Biochemistry, King's College London Medical School, London; Neurochemistry Department, Regional Neurosciences Centre, Newcastle General Hospital, Newcastle upon Tyne, UK; Liver Study, Veterans Affairs Medical Center and Departments of Internal Medicine and Biochemistry/Molecular Biology, University of Nebraska College of Medicine, Omaha, NE; James Cook University, Townsville, Australia; and the Department of Medicine, Salem Medical Centre, Heidelberg, Germany.

Submitted March 6, 2001; accepted June 14, 2001.

Supported in part by Grant No. AA09384 from the National Institute on Alcohol Abuse and Alcoholism and the British Council for UKGerman travel (to H.K.S. and T.J.P.).

Address reprint requests to $M$. Koll, Department of Nutrition and Dietetics, School of Life Sciences, King's College London, FranklinWilkins Bldg, 150 Stamford St, London SE1 9NN, UK.

Copyright (C) 2002 by W.B. Saunders Company

0026-0495/02/5101-0003\$35.00/0

doi:10.1053/meta.2002.28967 
muscle proteolysis, although more recently, it has been shown that in urine of the alcohol-fed rat, the ratio of 3-methylhistidine/creatinine increases. ${ }^{19}$

Thus, it is apparent that there is conflicting data regarding whether either a decrease or increase in muscle protein breakdown occurs in response to ethanol exposure. To address this and a number of other outstanding issues, we undertook the present investigations. By measuring the maximal activities of enzymes as indices of the capacity for protein degradation, this study was performed to: (1) clarify if muscle proteolysis is more susceptible to acute (2.5 hours) alcohol dosage, and if there may be age-related sensitivity to this phenomenon; (2) determine which proteolytic pathway (lysosomal, cytoplasmic, proteasomal, and $\mathrm{Ca}^{2+}$-activated) may be affected by chronic alcohol-feeding, using a standard feeding protocol of 6 weeks treatment; (3) investigate if there are alterations in protease activities during chronic alcohol-feeding at specific time points; (4) test the hypothesis that there may be a sensitization of muscle protease activity after superimposing acute alcohol treatment on chronic alcohol-fed rats; and (5) ascertain whether alcohol (in vitro) or acetaldehyde (in vitro and in vivo) may be mediators of alcohol-induced muscle damage. Cyanamide, a potent aldehyde dehydrogenase inhibitor, was used to elevate acetaldehyde levels in vivo.

\section{MATERIALS AND METHODS}

\section{Materials and Animals}

All reagents were obtained from BDH or the Sigma Chemical Co (Poole, Dorset, UK or St Louis, MO). Male Wistar rats were obtained from Charles River or Harlan Olac (Kent, UK). They were maintained usually for 1 week on a 12 hours light/12 hours dark cycle (beginning at $8.00 \mathrm{AM})$ in a temperature and humidity controlled Animal House, licensed and approved by the Home Office, prior to use.

Study 1: The effect of acute ethanol dosing in immature and mature rats. The effect of acutely administered alcohol $(75 \mathrm{mmol} / \mathrm{kg}$ body weight [BW]; intraperitoneal [IP], 2.5 hours prior to killing) on muscle protease activities was investigated. Controls were treated with identical volumes of saline $(0.15 \mathrm{~mol} / \mathrm{l} \mathrm{NaCl}, \mathrm{IP})$. Rats had free access to a standard laboratory chow diet and water throughout the study. The experimental groups were as follows: (1) ad libitum control, immature rats; (2) ad libitum + alcohol (2.5 hours), immature rats; (3) ad libitum control, mature rats; (4) ad libitum + alcohol (2.5 hours), mature rats. BW means of the rats $( \pm$ SEM) were $114 \pm 1 \mathrm{~g}$ (groups 1 and 2 ), $352 \pm 7 \mathrm{~g}$ (group 3), and $356 \pm 9 \mathrm{~g}$ (group 4). These were sexually immature and mature adult rats and have been labeled immature and mature rats for convenience, ie, approximately 5 weeks and 11 weeks old, respectively. Rats were killed 2.5 hours after saline or ethanol dosage. The leg was removed and rapidly cooled in an ice/water mixture, the gastrocnemius was dissected, weighed, and after it had been blotted dry, immediately snap-frozen in liquid nitrogen and stored at $-70^{\circ} \mathrm{C}$ for further analysis.

Study 2: The effect of chronically (6 weeks feeding) administered alcohol on muscle protease activities. For pair-feeding studies, animals were kept in individual wired-bottom cages to prevent coprophagy. Initially, the rats weighed 60 to $65 \mathrm{~g}$. Rats were fed ad libitum on a standard laboratory chow until their BW was between 80 to $85 \mathrm{~g}$ (approximately 4 weeks of age), at which time they were divided into groups of equal BW and used as described below. For the study of cathepsin B and D activities in large rats, rats with an initial BW of $278 \pm 8$ were used. Control rats were fed a nutritionally complete liquid diet, prepared from a commercially available food drink, sup- plemented with glucose, casein, and a vitamin mixture, according to the Lieber-DeCarli feeding protocol. The proportions of fat, protein, and carbohydrate in the control diet were $30 \%, 15 \%$, and $55 \%$ of total energy, respectively. ${ }^{20}$ Treated rats were given the same diet ad libitum in which $35 \%$ of total dietary energy as glucose was replaced by an isocaloric amount of alcohol. ${ }^{21}$ Control and alcohol-containing diets were isolipidic, isonitrogenous, and isoenergetic. Control rats were given identical dietary quantities compared with their pair-matched alcohol-treated rats. The diets were freshly prepared each day and presented to the animals between 9.00 AM and 12:00 PM. The experimental groups were as follows: (1) control, 6 weeks pair-feeding; (2) alcohol-fed, 6 weeks. The final BWs at the time of killing were $215 \pm$ $2 \mathrm{~g}$ for the control animals and $187 \pm 3 \mathrm{~g}$ for the alcohol-fed rats. ${ }^{17}$ The final BWs for the large rats were $390 \pm 9$ for the control and $361 \pm 8$ for the alcohol-fed group. ${ }^{17}$ The killing procedures were as above, except for the assay of the calcium-activated proteases, for which whole leg muscles were dissected, due to the nature of the subsequent assay procedure.

Study 3: Sequential changes in cathepsin $B$ and $D$ activities in gastrocnemius muscle during 6 weeks ethanol-feeding. In this study rats, approximately 7.5 weeks of age $(85 \pm 2 \mathrm{~g})$, were pair-fed for up to 6 weeks as described above. The experimental groups were as follows (1) control, pair-fed; (2) alcohol-fed. After 3, 7, 14, 28, and 42 days of pair-feeding, rats were killed. One control group was killed on the day the pair-feeding commenced. The killing procedures were as above. The final BWs were $225 \pm 3 \mathrm{~g}$ for the control group and $197 \pm$ $4 \mathrm{~g}$ for the alcohol group.

Study 4: The effect of superimposition of an acute bolus of alcohol in rats that received alcohol for 4 weeks. In this study rats, approximately 4 weeks of age, were pair-fed for 4 weeks as described above. Alcohol-fed rats that received an acute bolus of alcohol $(75 \mathrm{mmol} / \mathrm{kg}$ BW; IP, 2.5 hours prior to killing) had the alcohol in their diet withdrawn 24 hours earlier and replaced by isocaloric glucose. Controls were either pair-fed the nonalcohol-containing diet or treated with identical volumes of saline $(0.15 \mathrm{~mol} / \mathrm{L} \mathrm{NaCl}, \mathrm{IP})$. The experimental groups were as follows: (1) control, 4 weeks pair-feeding; (2) alcoholfed, 4 weeks + saline; (3) alcohol-fed, 4 weeks + acute alcohol. After 4 weeks of pair-feeding, the mean final BWs $( \pm$ SEM) at the time of killing were $186 \pm 7 \mathrm{~g}$ for group $1,177 \pm 4 \mathrm{~g}$ for group 2 , and $173 \pm$ 6 for group 3. The killing procedure was as above.

Study 5: The effect of alcohol and acetaldehyde in vitro on the activities of cathepsin B and D. Rats were fed alcohol for 6 weeks (plus their pair-fed controls) and a group fed ad libitum on chow diet. The BWs were approximately $83 \pm 4 \mathrm{~g}$ at the start of the study for all groups, $205 \pm 3 \mathrm{~g}$ for control, and $183 \pm 5 \mathrm{~g}$ for alcohol groups at the end of the experiment and $388 \pm 7 \mathrm{~g}$ for the ad libitum-fed rats. To muscle homogenates $(1: 10 \mathrm{wt} / \mathrm{vol})$, alcohol or acetaldehyde was added at a concentration of $200 \mathrm{mmol} / \mathrm{L}$ or $200 \mu \mathrm{mol} / \mathrm{L}$, respectively, as described previously. ${ }^{22}$ Ethanol and acetaldehyde were added to the ice-cold incubation buffer immediately before use to minimize loss (especially of acetaldehyde) through evaporation. The addition of ethanol or acetaldehyde was designed to determine whether alcohol treatment could alter the susceptibility of proteases to these agents.

Study 6: The effects of raising acetaldehyde levels in vivo on the activities of muscle proteases. For this study, rats, approximately 5 weeks of age, had free access to a standard laboratory chow diet and water. Cyanamide $(0.5 \mathrm{mmol} / \mathrm{kg} \mathrm{BW}, \mathrm{IP})$, a potent aldehyde dehydrogenase inhibitor, ${ }^{23}$ was given as a bolus 3 hours before killing. Acute (75 mmol $/ \mathrm{kg}$ BW, IP) alcohol was administered 2.5 hours before killing. Controls to both treatments were treated with identical volumes of saline $(0.15 \mathrm{~mol} / \mathrm{L} \mathrm{NaCl}, \mathrm{IP})$. The experimental groups were as follows: (1) control + saline; (2) cyanamide + saline; (3) control + alcohol (2.5 hours); (4) cyanamide + alcohol (2.5 hours). The mean BWs ( \pm SEM) were $113 \pm 2 \mathrm{~g}$ (group 1) and $113 \pm 1 \mathrm{~g}$ (groups 2, 3, 
and 4). Rats were killed 2.5 hours after the last saline or ethanol injections. The killing and dissection procedure was above. It is important to note that the rats used in groups 1 and 2 above were identical to those described for groups 1 and 2 in study 1 . The reason for this dual presentation of data was to minimize the use of animals, according to Home Office guidelines.

\section{Materials and Sample Processing}

Muscle samples (approximately $50 \mathrm{mg}$ ) were homogenized using an Ultra-Turrax homogenizer (I.K.A Labortechnik, Germany; $2 \times 30$ seconds at 15,000 rpm); a 1:20 (wt/vol) tissue/buffer homogenate was prepared in a buffer containing $0.15 \mathrm{~mol} / \mathrm{L} \mathrm{NaCl}, 1 \mathrm{mmol} / \mathrm{L}$ dithiothreitol (DTT), $3 \mathrm{mmol} / \mathrm{L} \mathrm{NaN}_{3}$, and either $50 \mathrm{mmol} / \mathrm{L}$ Tris/acetate buffer, pH 7.5 (cytoplasmic proteases assays), or $50 \mathrm{mmol} / \mathrm{L}$ sodium acetateacetic acid buffer, pH 5.5 (lysosomal proteases assays). Proteases associated with lysosomes/microsomes are released into the soluble phase (without the use of detergents) following disruption via UltraTurrax homogenization. Tissue homogenates were centrifuged at $2,000 \times g$ for 10 minutes, and the supernatant (containing $>85 \%$ of total tissue activity for each protease type) was retained for proteolytic enzyme assays. ${ }^{24}$

\section{Proteolytic Enzyme Assays}

Enzyme (0.05 $\mathrm{mL}$ supernatant) was incubated with the appropriate assay medium (total volume, $0.3 \mathrm{~mL}$ ) at $37^{\circ} \mathrm{C}$ (10 to 120 minutes), and the reaction terminated by addition of $0.6 \mathrm{~mL}$ of ethanol. ${ }^{24}$ The fluorescence of the liberated aminoacyl 7-amino-4-methylcoumarin (AMC) was measured by reference to a tetraphenylbutadiene fluorescence standard block ( $\lambda$ ex $380 \mathrm{~nm}, \lambda$ em $440 \mathrm{~nm}$ ). Assay blanks were run in which the enzyme was added to the medium immediately before ethanol addition. Assay conditions were modified for samples with high enzyme activity, such that the extent of substrate utilization never exceeded $15 \%$. Stock substrate solutions $(2.5 \mathrm{mmol} / \mathrm{L})$ were prepared in $10 \%(\mathrm{vol} / \mathrm{vol})$ ethanol. ${ }^{24}$

Assays were performed for the following enzyme types: Alanyl aminopeptidase (EC 3.4.11.14), arginyl aminopeptidase (EC 3.4.11.6), leucyl aminopeptidase (EC 3.4.11.1), dipeptidyl aminopeptidase I (EC 3.4.14.1), dipeptidyl aminopeptidase II (EC 3.4.14.5), dipeptidyl aminopeptidase IV (EC 3.4.14.5), tripeptidyl aminopeptidase (EC 3.4.14.9), proline endopeptidase (EC 3.4.21.26), Cathepsin B (EC 3.4.22.1) or cathepsin B + L (EC 3.4.22.15), Cathepsin D (EC 3.4.23.5), Cathepsin H (EC 3.4.22.16), and multicatalytic proteasome (EC 3.4.99.46). Full details of reagents and assay conditions can be found elsewhere. ${ }^{24,25}$

Some data (Fig 2) were originally analyzed as $\mu \mathrm{U} / \mathrm{mg}$ wet weight and $\mathrm{A}_{280} / \mathrm{mg}$ wet weight/h, respectively, 22 but converted to the same units as used in Fig 1 to ensure comparability of the data. Based on the assumption that control rats in studies 2 and 3 at the end of 6 weeks glucose feeding gave identical protease data, the conversion factors (f) were as follows: for cathepsin $\mathrm{B}$ ( $\mu \mathrm{U} / \mathrm{mg}$ wet weight) into $\mathrm{nmol} / \mathrm{h} / \mathrm{mg}$ protein $\mathrm{f}=17.9 / 10.5$, for cathepsin $\mathrm{D}\left(\Delta \mathrm{A}_{280} / \mathrm{mg}\right.$ wet weight $\left./ \mathrm{h}\right)$ into units $/ \mathrm{h} / \mathrm{mg}$ protein $\mathrm{f}=5.17 / 6.05$.

Assay conditions for multicatalytic proteasome (EC 3.4.99.46) were as follows: chymotrypsin-like activity (for study 4): $50 \mathrm{mmol} / \mathrm{L}$ Tris/ acetate buffer $\mathrm{pH} 7.5$ at $37^{\circ} \mathrm{C}, 5 \mathrm{mmol} / \mathrm{L} \mathrm{CaCl}, 1 \mathrm{mmol} / \mathrm{L}$ DTT, 0.25 $\mathrm{mmol} / \mathrm{L}$ Glu-Gly-Gly-Phe-AMC; multicatalytic proteasome (EC 3.4.99.46), trypsin-like activity (for study 4 ): $50 \mathrm{mmol} / \mathrm{L}$ glycine buffer pH 9.5 at $37^{\circ} \mathrm{C}, 1 \mathrm{mmol} / \mathrm{L}$ DTT, $0.25 \mathrm{mmol} / \mathrm{L} \mathrm{CBZ}$ (carboxylbenzyl)Gly-Gly-Arg-AMC.

For the proteasome proteolytic assay in study 2, an alternative method was used to that above, although the chymotrypsin- and trypsin-like activities of the multicatalytic protease were determined in each case. Portions of frozen muscle samples from ethanol-fed rats and their pair-fed controls were prepared as 1:10 (wt/vol) homogenates. Each gram of frozen tissue was suspended in $9 \mathrm{vol}$ of $0.1 \mathrm{~mol} / \mathrm{L}$
Tris- $\mathrm{HCl}(\mathrm{pH} 7.5)$ containing $0.25 \mathrm{~mol} / \mathrm{L}$ sucrose and homogenized using 4 to 5 strokes of a Tissuemizer spinning at $1,000 \mathrm{rpm}$. Portions of the crude extracts were centrifuged at $105,000 \times g$ for 1 hour to obtain the high-speed supernatant or cytosolic fraction. The latter fraction was used as the source of proteasomes. Muscle cytosolic fractions were assayed for their chymotrypsin-like (N-succinyl-LeuLeu-Val-Tyr-AMC hydrolysis), trypsin-like (N-t-Boc-Leu-Ser-ThrArg-AMC hydrolysis), and peptidylglutamyl peptide hydrolase (NCBZ-Leu-Leu-Glu- $\beta$-naphthylamide hydrolysis) activities. A detailed account of the assay substrates and conditions can be found elsewhere. ${ }^{26}$

\section{Protein Assays}

Protein levels in tissue supernatants were determined by the Lowry method $^{27}$ or using the dual-wavelength spectrophotometric absorbance method 28

\section{Statistics}

Values for protease activities are means \pm SEM for $n=4$ to 8 observations. Differences between means were assessed using Student's $t$ test for paired samples for the chronic and in vitro study, otherwise an unpaired $t$ test was employed using the LSD test for comparisons between multiple groups. Significance was assumed when $P<.05$

\section{RESULTS}

In the age-related study (study 1), a different response of protease activities in skeletal muscle from immature and mature rats was observed following acute alcohol dosage. In mature rats, the activities of the 3 cytoplasmic proteases, alanyl aminopeptidase, arginyl aminopeptidase, and leucyl aminopeptidase were reduced $(-30 \%, P<.05 ;-40 \%, P<.001$ $-27 \%, P=.057$, respectively, Fig 1). The activity of the lysosomal enzyme dipeptidyl aminopeptidase II decreased by $32 \%(P<.01$, Fig 1$)$, and the chymotrypsin- and trypsin-like activities of the multicatalytic proteasome were reduced by $-34 \%, P<.01$ and $-24 \%, P<.05$, respectively (Fig 1). However, in these mature rats, there was no measurable effect of acute alcohol dosage on the activities of cytoplasmic prolyl-, tripeptidyl aminopeptidase, and dipeptidyl aminopeptidase IV, or lysosomal cathepsins B, D, H, and L dipeptidyl aminopeptidase I activities (data not shown for brevity).

In immature rats, there was no effect on any of the cytoplasmic (alanyl-, arginyl-, leucyl-, prolyl-, tripeptidyl-aminopeptidase, and dipeptidyl aminopeptidase IV), lysosomal (cathepsins $\mathrm{B}, \mathrm{D}, \mathrm{H}$, and L, dipeptidyl aminopeptidase I and II), or proteasomal (chymotrypsin- and trypsin-like) protease activities (data not shown for brevity). It is important to emphasize that studies were performed separately on either immature or mature rats and, therefore, it would be imprudent to ascribe age-related changes in protease activities in control animals.

In study 2 , chronic ethanol feeding did not affect the activities of calpastatin, microcalpain, or millicalpain (data not shown for brevity). Expression of data in terms of the ratios of calpastatin/microcalpain and calpastatin/millicalpain was performed to ascertain if there may have been subtle effects on relative activities, which would have otherwise been masked by inter-rat variability. However, these ratios were also unaltered (data not shown for brevity).

The activities of the cytoplasmic and lysosomal proteases 

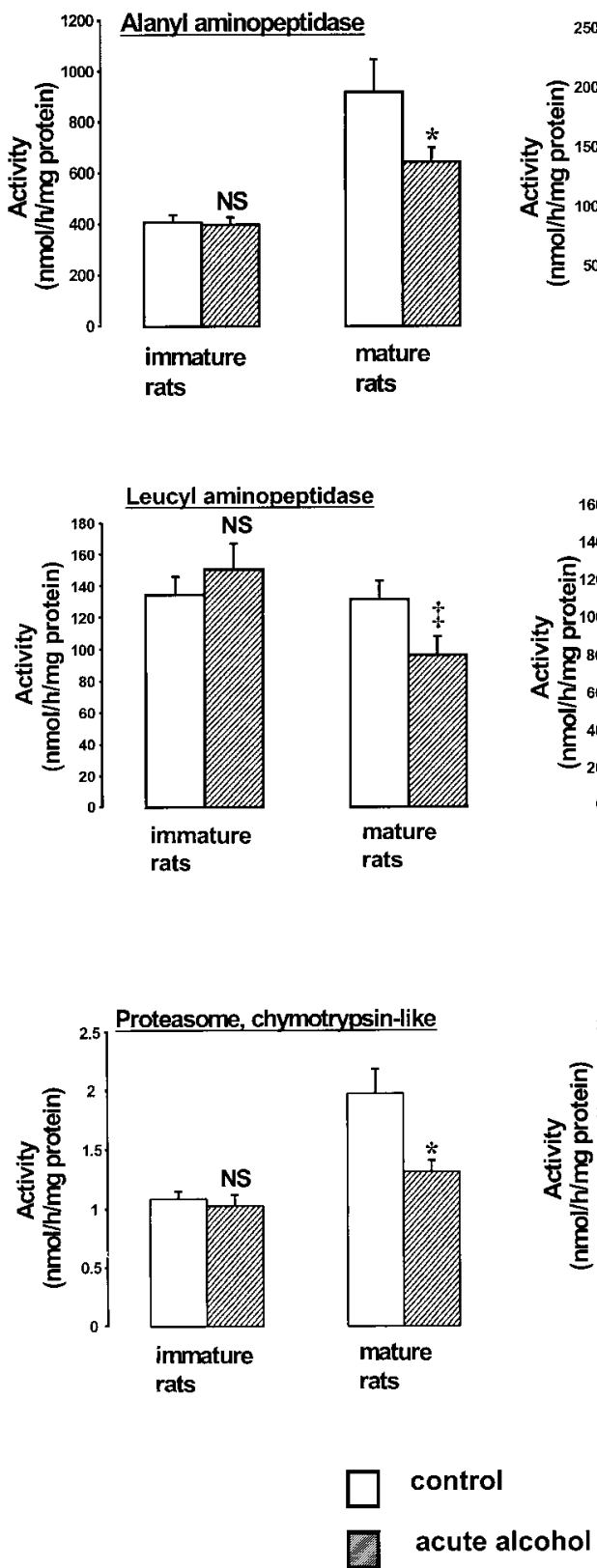
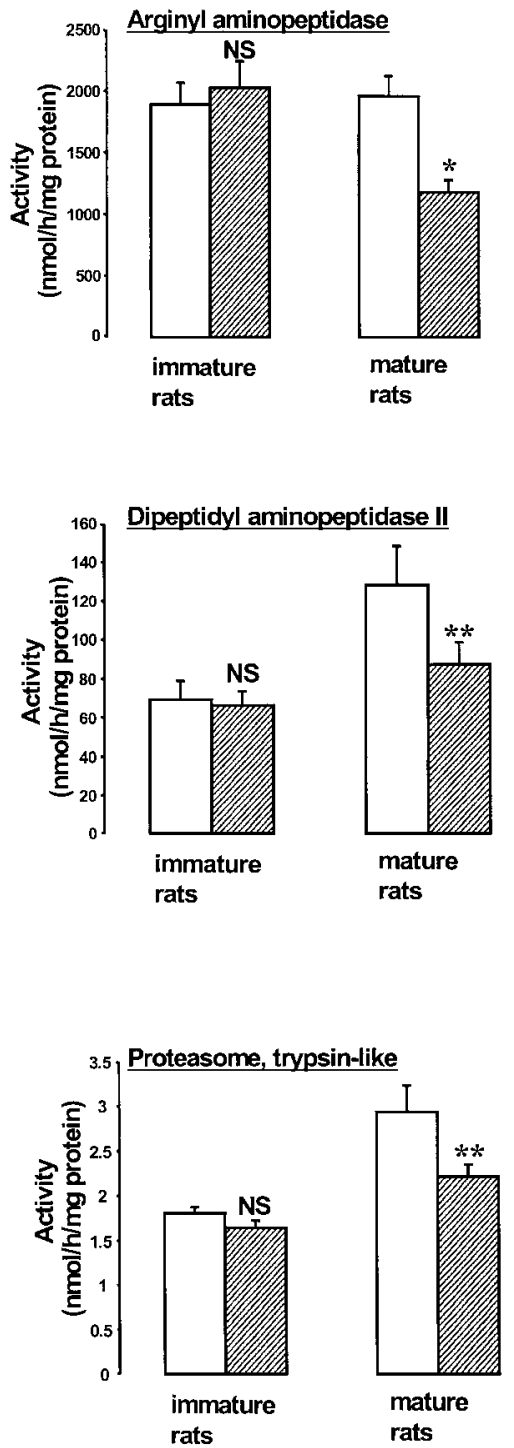

Fig 1. All units as mean \pm SEM $n$ mol substrate hydrolyzed $/ \mathrm{h} / \mathrm{mg}$ soluble protein. The acute alcohol dosage ( $75 \mathrm{mmol} / \mathrm{kg} \mathrm{BW} \mathrm{IP)}$ was administered 2.5 hours before killing to ad libitum-fed rats. The mean BWs were $114 \mathrm{~g}$ for the immature rats (control and acute alcohol), $352 \mathrm{~g}$ for the control mature rats, and $356 \mathrm{~g}$ for the acute alcohol mature rats. Differences between means were assessed with analysis of variance (ANOVA) followed by Student's $\boldsymbol{t}$ test using LSD. $\mathrm{n}=\mathbf{6}$ (immature rats), $\mathrm{n}=6$ to 8 (mature rats). ${ }^{\ddagger} P=.057 ;{ }^{*} P<.05 ;{ }^{*} P<$ 01 . and the chymotrypsin- and trypsin-like and the peptidylglutamyl-peptide hydrolase activities of the multicatalytic proteasome were similarly unaffected after 6 weeks alcohol treatment in immature animals (data not shown for brevity), as well as the cathepsin B and D activities in mature animals (data not shown for brevity).

To ascertain if there were subtle time-related changes in protease activities that may have been overlooked by analysis of a single 6-week time point, we assayed cathepsin B and D activities in rats fed alcohol for 3 days, 1, 2, 4, and 6 weeks (study 3). However, sequential changes in cathepsin B and D activities were not significant (data not shown for brevity). It should be noted that at days 7 and 14 of chronic alcohol feeding, the activity of cathepsin B was marginally reduced
$(-14 \%, P=.055$ and $-18, P=0.053$; data not shown for brevity). The rationale behind the selection of cathepsin B and D only was the limitation in time and sample availability. Cathepsin B and D have been shown to be important for the degradation of contractile proteins, and it has also been suggested that the rate of myofibrillar degradation is increased in alcohol feeding. ${ }^{19}$ In mature rats, chronic alcohol treatment for 6 weeks did not significantly increase cathepsins B or D activities, and cathepsin D activities may have been actually deceased in these mature rats $(-8 \%, P=.056$; data not shown for brevity).

When alcohol was withdrawn for 24 hours from chronic alcohol-fed rats and then an acute bolus of alcohol administered (study 4), the activity of the cytoplasmic enzyme proline ami- 
Table 1. Effect of Superimposing Acute (2.5 hours) Alcohol Dosage on Chronic (4 weeks) Alcohol-Fed Rats on Protease Activity in the Gastrocnemius Muscle of Immature Rats

\begin{tabular}{|c|c|c|c|c|}
\hline & \multicolumn{3}{|c|}{ Activity (nmol/h/mg protein) } & \multirow[b]{2}{*}{$P$ Value } \\
\hline & Control & Alcohol & $\begin{array}{c}\text { Difference as } \\
\% \text { Control }\end{array}$ & \\
\hline \multicolumn{5}{|l|}{ Cytoplasmic enzymes. } \\
\hline \multicolumn{5}{|c|}{ Proline aminopeptidase } \\
\hline Chronic & $1,133 \pm 81$ & $959 \pm 113$ & -15 & .3864 \\
\hline Chronic + acute & & $864 \pm 67$ & -24 & .0391 \\
\hline \multicolumn{5}{|c|}{ Multicatalytic proteasome. } \\
\hline Chronic & $1.69 \pm 0.12$ & $1.49 \pm 0.11$ & -12 & .2900 \\
\hline Chronic + acute & & $1.30 \pm 0.09$ & -23 & .0512 \\
\hline \multicolumn{5}{|l|}{ Trypsin-like activity } \\
\hline Chronic & $2.92 \pm 0.29$ & $2.17 \pm 0.11$ & -26 & .0786 \\
\hline Chronic + acute & & $2.27 \pm 0.13$ & -22 & .0362 \\
\hline
\end{tabular}

NOTE. All units as mean \pm SEM nmol substrate hydrolyzed/h/mg soluble protein. Only significant changes are displayed. Chronic alcohol-fed rats were fed for 4 weeks on a liquid diet containing $35 \%$ of dietary energy as ethanol. Controls were fed identical amounts of diet in which ethanol was replaced by isocaloric glucose. The acute alcohol dosage $(75 \mathrm{mmol} / \mathrm{kg} \mathrm{BW} \mathrm{IP)}$ was administered 2.5 hours before killing. The mean body weights were $186 \mathrm{~g}$ for the controls, $177 \mathrm{~g}$ for alcohol-fed rats, and $173 \mathrm{~g}$ for the rats that received chronic + acute alcohol. Differences between means were assessed using Student's $t$ test using LSD, except for differences between chronic control and chronic alcohol groups for which a paired $t$ test was used ( $\mathrm{n}=5$ to 8 ).

nopeptidase was subsequently decreased by $24 \%(P<.05$, Table 1). Additionally, the chymotrypsin- and trypsin-like activities of the multicatalytic proteasome were both reduced by such coimposition $(-23 \%, P=.051$ and $-22 \%, P<.05$, respectively). The superimposition of alcohol regimes did not alter the activities of the other proteases investigated including cytoplasmic alanyl-, arginyl-, leucyl-, tripeptidyl-aminopeptidase, and dipeptidyl aminopeptidase IV or lysosomal cathepsins B, D, H, and L, dipeptidyl aminopeptidase I and II (data not shown for brevity).

Addition of alcohol (200 mmol/L) or acetaldehyde (200 $\mu \mathrm{mol} / \mathrm{L}$ ) to homogenates of muscles from ad libitum, chronic alcohol-fed and pair-fed control rats did not affect cathepsin B activity in vitro (study 5). However, cathepsin D activity was decreased after addition of ethanol in muscle homogenates of control (ie, glucose fed), alcohol, and ad libitum (ie, chow-fed) fed rats $(P=.059, P<.05, P<.05$, respectively; Fig 2$)$. Acetaldehyde in vitro also reduced cathepsin D activities in control, alcohol, and ad libitum-fed rats (all at $P<.05$; Fig 2). In contrast, raising acetaldehyde levels in vivo by cyanamide pretreatment (study 6) did not alter the activities of cathepsin D or any other of the other lysosomal (cathepsins B, H, and L, dipeptidyl aminopeptidase I and II), cytoplasmic (alanyl-, arginyl-, leucyl-, prolyl-, tripeptidyl-aminopeptidase, and dipeptidyl aminopeptidase IV) or proteasomal (chymotrypsin-, trypsin-like) protease activities (data not shown for brevity).

\section{DISCUSSION}

\section{Methodologic Considerations}

There are no reported direct methods for measuring the rate of muscle protein breakdown in vivo in the rat in the absence of invasive procedures. As tissue proteins have the potential to be broken down by proteases (lysosomal and nonlysosomal, including components of the proteosomal system), it follows that the activities of these enzymes may be convenient for assessing the impact of pathogenic treatments on protein degradation. In practice, they only provide an index of the capacity for protein degradation. Nevertheless, studies have shown that there is a very good correlation between the in vitro rates of protein degradation as assessed by release of tyrosine and the activities of muscle proteases, for example, cathepsin B and D. ${ }^{29}$

In the present study, the results are limited to maximal activities of proteolytic enzymes. Such measurements give the capacity of a system, although they cannot be used to say anything about the actual rate of amino acid flux in vivo.

\section{Sensitivity of Proteases in Mature Rats to Acute Alcohol}

We have demonstrated that only protease activities in muscle of mature rats were susceptible to the effects of acute alcohol, as reflected by reductions in selected cytoplasmic, lysosomal, and proteasomal enzyme activities. In contrast, no changes in protease activities were observed in immature rats in response to acute ethanol dosage in vivo. Studies on skeletal muscle protein synthesis support the concept that immature and mature rats have differential responses to this macrotoxin. ${ }^{17,30}$ Thus, the fractional rate of protein synthesis in skeletal muscle (gastrocnemius) is greater in immature alcohol-fed rats than in mature ones, and this is manifested as an early myopathic lesion as defined by reduced protein content. ${ }^{30}$ Paradoxically, the effect of chronic alcohol treatment on protein synthesis in mature rats seems to be slightly greater than in immature rats. ${ }^{31}$ Also, the decrease in the calculated rate of protein degradation, although reduced in both immature and mature rats, is greater in mature rats. ${ }^{17,30}$ In the present study, we did not observe a reduction in proteolytic activities in immature rats in response to acute alcohol, although we showed a greater susceptibility in mature rats. However, it has been established that the antioxidant defense system in skeletal muscle increases with age, but type 2 fibers have been found to be more susceptible to age- 
Cathepsin B
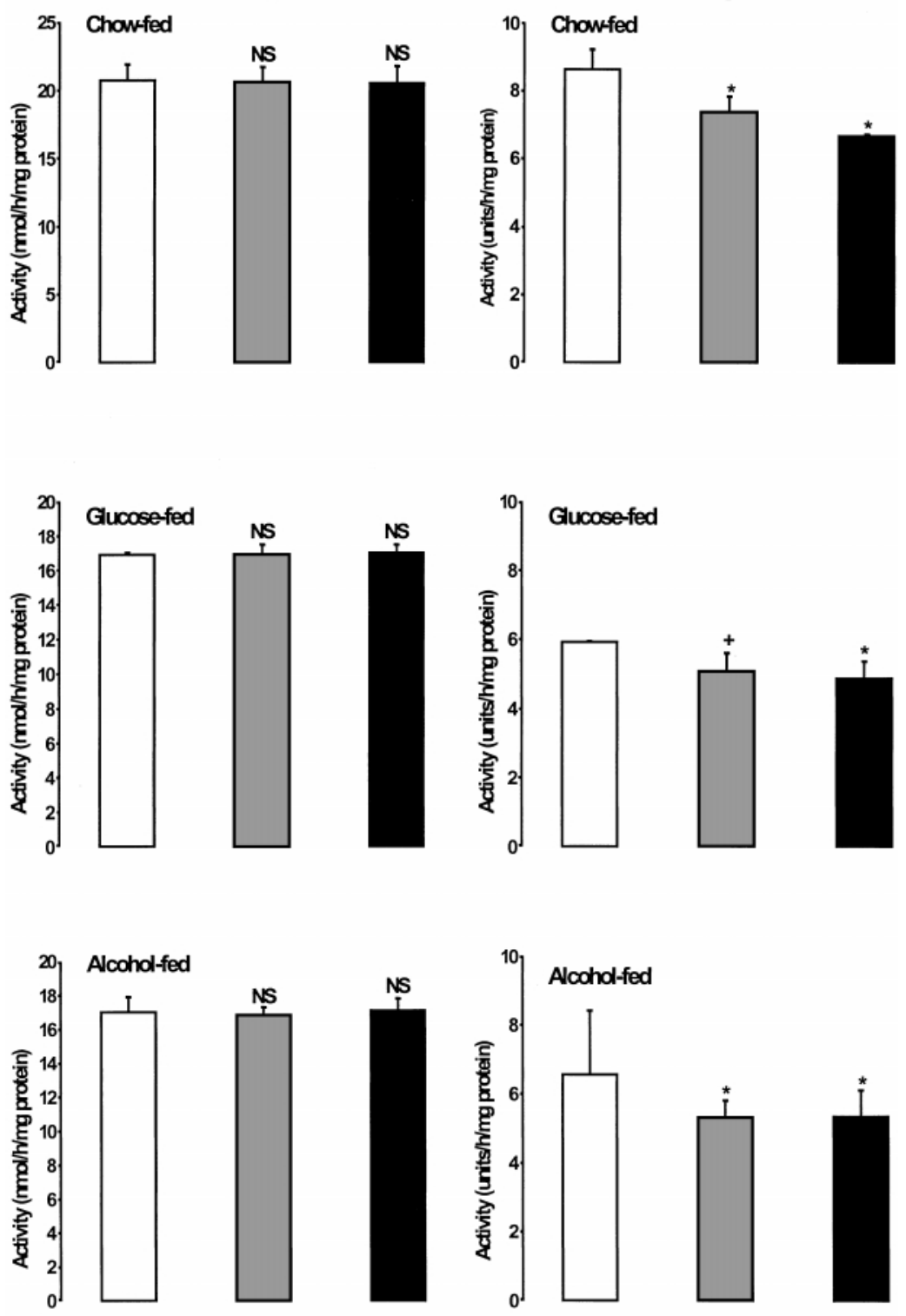

Fig 2. Rats were fed alcohol for 6 weeks, controls were pair-fed. Ad libitum rats were untreated and had free access to food and water. Alcohol (200 $\mathrm{mmol} / \mathrm{L})$ or acetaldehyde $(200 \mu \mathrm{mol} / \mathrm{L})$ were added to muscle homogenates (1:10 wt/vol) or no addition was made as reference values. The mean BWs were $205 \mathrm{~g}$ for control rats, $183 \mathrm{~g}$ for the ethanol-dosed rats, and $388 \mathrm{~g}$ for the ad libitumfed rats. Differences between means were assessed using Student's $t$ test for paired samples. $\mathrm{n}=5$ to $6 .{ }^{+} \boldsymbol{P}=.059 ;{ }^{*} P<.05$. related oxidative stress. ${ }^{32}$ This may explain, but does not prove, the differential susceptibility of skeletal muscle to acute alcohol dosage in mature rats.

A previous study has shown that 24 hours after acute alcohol dosage, reduced muscle cytoplasmic protease (alanyl aminopeptidase and tripeptidyl aminopeptidase) activities occurs in immature rats. ${ }^{15}$ However, we do not believe that the aforementioned studies contradict the present data. The former study may reflect a postexposure or rebound phenomena at 24 hours after alcohol dosage, as there was no circulating blood alcohol detectable at 24 hours, ${ }^{15}$ whereas the present study shows the effects of acute alcohol, which is reflected in markedly increased serum alcohol concentrations (mean ethanol levels in glucose fed + acute alcohol and chronic + acute alcohol groups were approximately 250 to $300 \mathrm{mg} \%$ ).

\section{Chronic Alcohol Does Not Affect Muscle Protease Activity}

Six weeks of chronic alcohol feeding did not alter the activities of any of the proteases assayed. Potentially, this implies 
that the reduction in muscle protein content that occurs after 6 weeks of alcohol feeding in the young, ie, immature, rat is due to alterations in protein synthesis alone. ${ }^{33}$ This conclusion, however, is at variance with studies suggesting that a decrease in protein degradation occurs. ${ }^{17}$ It is possible that greater perturbations in protease activities may have occurred at intermediate time points rather than at 6 weeks. However, cathepsins B and $\mathrm{D}$ did not show any overt alteration at any of the intermediate time points (3 days, 1, 2, 4, and 6 weeks). Although we were unable to measure other proteases at all of these intermediate time points due to restrictions in time and tissue availability, the data for the time course study is consistent with results obtained from rats killed at 4 weeks and 6 weeks. Alternatively, it can be argued there are methodologic limitations in the model of measuring muscle protease activities in vitro to reflect protein degradation in rats fed alcohol in vivo, and this could explain these divergent results. For example, pathologic lesions in protein turnover may arise episodically, as a consequence of fluctuations in alcohol levels, coupled with the acute sensitization.

\section{Sensitization of Muscle Proteases to the Effects of Acute Alcohol in Superimposition Study}

In contrast to the lack of effect of chronic alcohol exposure, superimposing acute alcohol on chronic alcohol-fed rats showed a decrease in the activities of proline aminopeptidase and the chymotrypsin-and trypsin-like activities of the multicatalytic proteasome. No changes occurred in the lysosomal protease activities or in the activities of the other cytoplasmic enzymes assayed. The observed effects of combined chronic + acute alcohol may be due to alterations by acute alcohol alone, at least for the chymotrypsin- and trypsin-like activities of the proteasome. However, this argument may be flawed, as in acutely dosed mature rats, the activities of alanyl aminopeptidase, arginyl aminopeptidase, leucyl aminopeptidase, and dipeptidyl aminopeptidase II decreased (Fig 1), whereas only the activities of proline endopeptidase were decreased when acute alcohol was superimposed on chronic ethanol (Table 1). The reason for this is not clear, but consideration should be given to the fact that while the mature rats in study 1 and the chronic ethanol-fed rats in this study were the same age (ie, 8 weeks), rats used for the superimposition study were malnourished as a consequence of the pair-feeding protocol (for further discussion, see Preedy et $\mathrm{al}^{20}$ ). Malnutrition perturbs skeletal muscle proteolysis. ${ }^{34}$
Raising Acetaldehyde Levels In Vivo With Cyanamide or Addition of Alcohol and Acetaldehyde In Vitro.

Although we do not have alcohol or acetaldehyde levels for the rats dosed with alcohol and cyanamide, we have previously reported such data using identical protocols. ${ }^{35}$ Thus, mean blood levels of acetaldehyde $(\mu \mathrm{mol} / \mathrm{L})$ are control, 5; cyanamide, 5; ethanol, 31; and cyanamide + ethanol, 2,495. ${ }^{35}$ Corresponding acetaldehyde levels in muscle are $(\mu \mathrm{mol} / \mathrm{kg}) 51,52$, 62 , and 827, respectively. Raising acetaldehyde levels within cyanamide + ethanol-treated rats markedly reduces protein synthesis in skeletal muscle to greater than that with alcohol alone. ${ }^{36}$ In the present study, however, predosing ethanoltreated rats with cyanamide in vivo did not alter protease activities. However, we showed that $200 \mu \mathrm{mol} / \mathrm{L}$ acetaldehyde in vitro decreased cathepsin D activity, and similarly, supraphysiologic concentrations of either ethanol $(1.7 \mathrm{~mol} / \mathrm{L})$ or acetaldehyde $(17,000 \mu \mathrm{mol} / \mathrm{L})$ in human muscle homogenates reduced muscle protease activities. ${ }^{18}$ In contrast, cathepsin B activities were not affected by additions of either alcohol or acetaldehyde in the present (Fig 2) or previous ${ }^{18}$ studies. This data implies that (1) different proteases exhibit differential sensitivities to either alcohol or acetaldehyde; (2) supraphysiologic levels of acetaldehyde are required to reduce protease activities, but these levels are rarely encountered in intact rats. However, the interpretation of acetaldehyde levels is fraught with practical difficulties. The aforementioned in vitro studies did not take into account any time-dependent effects, nor how acetaldehyde might have caused localized effects with different regions of the muscle cell in vivo.

\section{Conclusions}

The reductions in protein breakdown, as reflected by reduced protease activities, distinguish the effects of alcohol from other catabolic states, such as sepsis or fasting, in which an increase in protein breakdown occurs. ${ }^{37,38} \mathrm{We}$ are uncertain how selective reductions in protease occurred other than the possibility that circulating ethanol and/or acetaldehyde may have been contributory, although very high levels are necessary to achieve this. It has been suggested that increased cytokine production (for example, TNF- $\alpha,{ }^{39}$ ) may alter proteolysis. Alternative processes include inactivation via possible acetaldehyde- or malondialdehyde-protein adduct formation. ${ }^{40}$

\section{ACKNOWLEDGMENT}

We wish to thank E.B. Cook for help with a part of this study.

\section{REFERENCES}

1. Preedy VR, Peters TJ, Why H: Metabolic consequences of alcohol dependency. Adverse Drug React Toxicol Rev 16:235-256, 1997

2. Reilly ME, Preedy VR, Peters TJ: Investigations into the toxic effects of alcohol on skeletal muscle. Adverse Drug React Toxicol Rev 14:117-150, 1995

3. Urbano-Marquez A, Estruch R, Navarro-Lopez F, et al: The effects of alcoholism on skeletal and cardiac muscle. N Engl J Med 320:409-415, 1989

4. Preedy VR, Salisbury JR, Peters TJ: Alcoholic muscle disease: Features and mechanisms. J Pathol 173:309-315, 1994

5. Duane P, Peters TJ: Nutritional Status in alcoholics with and without chronic skeletal muscle myopathy. Alcohol Alcohol 23:271277, 1988

6. Martin FC, Slavin G, Levi AJ, et al: Investigation of the organelle pathology of skeletal muscle in chronic alcoholism. J Clin Pathol 37:448-454, 1984

7. Martin FC, Peters TJ: Assessment in vitro and in vivo of muscle degradation in chronic skeletal muscle myopathy of alcoholism. Clin Sc 68:693-700, 1985

8. Slavin G, Martin F, Ward P, et al: Chronic alcohol excess is associated with selective but reversible injury to type $2 \mathrm{~B}$ muscle fibres. J Clin Pathol 36:772-777, 1983

9. Wassif WS, Preedy VR, Summers B, et al: The relationship 
between muscle fibre atrophy factor, plasma carnosinase activities and muscle RNA and protein composition in chronic alcoholic myopathy. Alcohol Alcohol 28:325-331, 1993

10. Preedy VR, Peters TJ: Protein metabolism in alcoholism, in Watson RR, Watzl B (eds): Nutrition and Alcohol. Boca Raton, FL, CRC, 1992, pp 143-189

11. Preedy VR, Peters TJ, Patel VB, et al: Chronic alcoholic myopathy: Transcription and translational alterations. FASEB J 8:11461151, 1994

12. Preedy VR, Reilly ME, Mantle D, et al: Free radicals and antioxidants in the pathogenesis of alcoholic myopathy, in Reznick AE, Packer DL, Sen CK, et al (eds): Free Radicals and Skeletal Muscle. New York, NY, Springer-Verlag, 1998, pp 283-293

13. Preedy VR, Patel VB, Reilly ME, et al: Oxidants, antioxidant and alcohol: Implications for skeletal and cardiac muscle. Front Biosci 4:e58-e66, 1999

14. Preedy VR, Adachi J, Ahmed S, et al: Pathogenic mechanisms in alcoholic myopathy, in Seitz HK, Ardawall G (eds): Alcoholinduced Pathologies. Leipzig, Germany, Johann Ambrosius Barth (in press)

15. Reilly ME, Mantle D, Richardson PJ, et al: Studies on the time-course of ethanol's acute effects on skeletal muscle protein synthesis: Comparison with acute changes in proteolytic activity. Alcohol Clin Exp Res 21:792-798, 1997

16. Teschner M, Schaefer RM, Weissinger F, et al: Chronic ethanol ingestion enhances catabolism and muscle protease activity in acutely uremic rats. Nephron 50:338-344, 1988

17. Preedy VR, Peters TJ: The effect of chronic ethanol ingestion on synthesis and degradation of soluble, contractile and stromal protein fractions of skeletal muscles from immature and mature rats. Biochem J 259:261-266, 1989

18. Mantle D, Falkous G, Peters TJ, et al: Effect of ethanol and acetaldehyde on intracellular protease activities in human liver, brain and muscle tissues in vitro. Clin Chim Acta 281:101-108, 1999

19. Takeda K, Yamauchi M, Sakamoto K, et al: A close association between testicular atrophy, muscle atrophy and the increase in protein catabolism after chronic ethanol administration. Alcohol Clin Exp Res 24:166A, 2000 (abstr)

20. DeCarli LM, Lieber CS: Fatty liver in the rat after prolonged intake of ethanol with a nutritionally adequate new liquid diet. J Nutr 91:331-336, 1967

21. Preedy VR, MaIntosh A, Bonner AB, et al: Ethanol dosage regimes in studies of ethanol toxicity: Influence of nutrition and surgical interventions. Addict Biol 1:255-262, 1996

22. Cook EB, Gove CD, Panos MZ, et al: Skeletal muscle protease activities are unaltered in cirrhotic rats but altered in response to ethanol and acetaldehyde in vitro. Alcohol Alcohol 30:203-209, 1995

23. DeMaster EG, Redfern B, Nagasawa HT: Mechanisms of inhibition of aldehyde dehydrogenase by nitroxyl, the active metabolite of the alcohol deterrent agent cyanamide. Biochem Pharmacol 55:20072015, 1998

24. Faiz MA, Harris JB, Maltin CA: Comparison of structural pro- tein and proteolytic enzyme levels in degenerating and regenerating rat muscle induced by Notechis scutatus venom. Comp Biochem Physiol 101:241-253, 1995

25. Blanchard PJ, Mantle D: Comparison of proteolytic enzyme levels in chicken, pig, lamb and rabbit muscle at point of slaughter: role in meat tenderisation post mortem. J Sci Food Agriculture 71:83-61, 1996

26. Donohue TMJ, Zetterman RK, Zhang-Gouillon ZQ, et al: Peptidase activities of the multicatalytic protease in rat liver after voluntary and intragastric ethanol administration. Hepatology 28:486-491, 1998

27. Lowry OH, Rosebrough NJ, Farr AL, et al: Protein measurement with the Folin Phenol reagent. J Biol Chem 193:265-275, 1951

28. Groves WE, Davis JFC, Sells BH: Spectrophotometric determination of microgram quantities of protein without nucleic acid interference. Anal Biochem 22:195-210, 1968

29. Goldspink DF, Lewis SEM: Age and activity related changes in three proteinase enzymes of rat skeletal muscle. Biochem J 230:833836, 1985

30. Preedy VR, Peters TJ: Changes in protein, RNA and DNA and rates of protein synthesis in muscle-containing tissues of the mature rat in response to ethanol feeding: A comparative study of heart, small intestine and gastrocnemius muscle. Alcohol Alcohol 25:489-498, 1990

31. Preedy VR, Peters TJ: The effect of chronic ethanol ingestion on protein metabolism in type-I-and type-II-fibre-rich skeletal muscles of the rat. Biochem J 254:631-639, 1988

32. Oh-Ishi S, Kizaki T, Yamashita H, et al: Alterations of superoxide dismutase iso-enzyme activity, content, and mRNA expression with aging in rat skeletal muscle. Mech Ageing Dev 84:65-76, 1995

33. Preedy VR, Peters TJ: Alcohol and skeletal muscle disease. Alcohol Alcohol 25:177-187, 1990

34. Horl WH, Wanner C, Schollmeyer P: Proteinases in catabolism and malnutrition. JPEN 11:98-103, 1987

35. Adachi J, Asano M, Ueno Y, et al: Acute effects of ethanol on 7-hydroxycholesterol in muscle and liver. Lipids 36:267-271, 2001

36. Preedy VR, Keating JW, Peters TJ: The acute effects of ethanol and acetaldehyde on rates of protein synthesis in type I and type II fibre-rich skeletal muscles of the rat. Alcohol Alcohol 27:241-251, 1992

37. Wing SS, Haas AL, Goldberg AL: Increase in ubiquitin-protein conjugates concomitant with the increase in proteolysis in rat skeletal muscle during starvation and atrophy denervation. Biochem J 307:639645, 1995

38. Hasselgreen PO, Fischer JE: Sepsis: Stimulation of energydependent protein breakdown resulting in protein loss in skeletal muscle. World J Surg 22:203-208, 1998

39. Vary TC: Regulation of skeletal muscle protein turnover during sepsis. Curr Opin Clin Nutr Metab Care 1:217-224, 1998

40. Worrall S, Niemela O, Parkkila S, et al: Protein adducts in type I and type II fibre predominant muscles of the ethanol-fed rat: Preferential localisation in the sarcolemmal and sub-sarcolemmal region. Eur J Clin Invest 31:723-730, 2001 